Brit. J. prev. soc. Med. (1963), 17, 1

\title{
SHORT-TERM CHANGES IN THE INCIDENCE OF MALFORMATIONS
}

\author{
BY \\ IAN LECK AND E. L. M. MILLAR \\ From the Department of Social Medicine, University of Birmingham
}

On at least two occasions, the examination of secular changes in the incidence of malformations has led to the identification of important aetiological agents. The discovery that rubella could cause congenital heart disease and cataract (Gregg, 1941) was based on studies of the incidence of these malformations. Similarly, the association between the taking of thalidomide in pregnancy and ectromelia was first demonstrated by inquiries carried out because defects of this type had become commoner (Lenz, 1961; McBride, 1961).

The increases in incidence caused by rubella and thalidomide were unnoticed until they became conspicuous enough to impress clinicians. It is clearly desirable that epidemics of malformations should be recognized before reaching such proportions, and there is therefore a need for the examination of secular trends in large populations of births. In the present communication, data for Birmingham children born in 1957-61 are analysed in this way.

\section{MATERIAL AND Methods}

Information about malformed children born in 1957-61 was obtained from the following sources:

(1) Public Health Department records of the birth histories, causes of death, and necropsy findings for stillbirths and for children who died before the end of 1961 while resident in Birmingham.

(2) The original necropsy reports of a few children whose Local Authority records stated that malformations were present but gave no particulars of them.

(3) Returns rendered by all Health Visitors in the city, giving particulars of living malformed children on their lists at the end of 1961.
(4) The hospital records of children admitted to local hospitals with malformations (excluding those who lived outside Birmingham at the time of death or the end of 1961).

Our propositi were therefore drawn from three groups of children born in 1957-61; those who were stillborn and had Birmingham parents, those who died before the end of 1961 while resident in Birmingham, and those living in Birmingham at the end of 1961. The total numbers of children in these three groups were obtained from Local Authority records.

The most reliable method of collecting data on the incidence of malformations is to examine all children at birth and then follow them up for a specified period. Compared to this method, the retrospective approach which was of necessity used in the present survey has two disadvantages. The first is that the surviving propositi were drawn from a smaller population than that to which the stillborn and dead children were related. In the case of the stillbirths, the related population consisted of all children resident in Birmingham at birth, and the same was approximately true for the dead children (since most of them died soon after birth). The surviving propositi, on the other hand, were drawn from children resident in Birmingham at the end of 1961. The numbers of children in these two groups-resident at birth and resident at the end of 1961-are compared in Table I (overleaf). As losses by emigration outweigh gains by immigration, the numbers resident at the end of 1961 were smaller than those resident at birth (excluding deaths), especially in the case of those born early in the period. In estimating the annual incidence of malformations among all Birmingham births, we have assumed that the malformation rates observed in children resident at the 
TABLE I

BIRMINGHAM RESIDENTS BORN IN 1957-61

\begin{tabular}{|c|c|c|c|c|c|c|c|c|c|c|c|}
\hline \multirow{2}{*}{\multicolumn{6}{|c|}{ Group }} & \multicolumn{6}{|c|}{ Year of Birth } \\
\hline & & & & & & 1957 & 1958 & 1959 & 1960 & 1961 & $\begin{array}{c}\text { Total } \\
1957-61\end{array}$ \\
\hline \multicolumn{2}{|c|}{ Number Resident at Birth $(a)$} & $\cdots$ & $\cdots$ & $\cdots$ & $\cdots$ & 19,322 & 19,714 & 19,770 & 21,198 & 22,038 & 102,042 \\
\hline \multirow{2}{*}{$\begin{array}{c}\text { Number Resident at } \\
\text { Death or End of } \\
1961\end{array}$} & $\begin{array}{l}\text { Stillborn } \\
\text { Died 1957-6i } \\
\text { Alive }\end{array}$ & $\begin{array}{l}\cdots \\
\cdots \\
\cdots\end{array}$ & $\begin{array}{l}\cdots \\
\cdots \\
\cdots\end{array}$ & $\begin{array}{l}\cdots \\
\cdots \\
\cdots\end{array}$ & $\begin{array}{l}\cdots \\
\cdots \\
\cdots\end{array}$ & $\begin{array}{r}416 \\
513 \\
15,929\end{array}$ & $\begin{array}{r}433 \\
541 \\
16.628\end{array}$ & $\begin{array}{r}418 \\
510 \\
17,114\end{array}$ & $\begin{array}{r}421 \\
507 \\
18,914\end{array}$ & $\begin{array}{r}444 \\
431 \\
20,359\end{array}$ & $\begin{array}{r}2,132 \\
2,502 \\
88,944\end{array}$ \\
\hline & Total $(b)$ & $\ldots$ & . & . & $\ldots$ & 16,858 & 17,602 & 18,042 & 19,842 & 21,234 & 93,578 \\
\hline \multicolumn{3}{|c|}{ Excess of Emigrants over Immigrants $(a)-(b)$} & $\ldots$ & $\ldots$ & $\ldots$ & 2,464 & 2,112 & 1,728 & 1,356 & 804 & 8,464 \\
\hline
\end{tabular}

end of 1961 applied also to all those resident at birth who were not stated to have died.

The second disadvantage of the methods used in this inquiry is that they can give complete ascertainment only in the case of malformations which were recognized at birth and either caused death, required hospital treatment, or came to the notice of health visitors. Types of malformations which do not always meet these requirements include: (i) Supernumerary digits and talipes, which are sometimes corrected by domiciliary treatment before the time of the Health Visitor's first visit; (ii) Hydrocephalus, mongolism, congenital heart disease, and dislocation of the hip, each of which was undiagnosed at birth in more than a quarter of cases in a previous Birmingham series (McKeown and Record, 1960; Leck, 1961). The children surveyed in the present inquiry were too young for ascertainment of the latter group of malformations to be complete.

In our search of hospital records (the fourth in our list of sources of data) we attempted only to trace malformations in respect of which the methods used seemed likely to give fairly complete ascertainment. The data from our other three sources (Local Authority records, necropsy reports, and Health Visitors' returns) related to malformations of all types. In the present communication we examine:

(1) Data from all four sources relating to those malformations which appear to be ascertainable in almost all cases;

(2) Data from the first three sources relating to certain other malformations, which were selected for study because they resembled some of those caused by thalidomide and because we were anxious to determine whether their incidence had increased since the introduction of this drug in 1958.

Fully Ascertainable Malformations

There were 102,042 stillbirths and live births to Birmingham residents in 1957-61. Table II (opposite) shows the incidence in this population of the more common malformations, excluding types not fully ascertainable by the methods used. Estimates of incidence among 56,760 births to Birmingham residents in 1950-52 are also given in the Table. These earlier estimates are taken from the reports mentioned above (McKeown and Record, 1960; Leck, 1961) and are based on $(a)$ the birth records of almost all Birmingham children and $(b)$ a 5-year follow-up of those who remained in the city. Like the present series, the earlier one was deficient in malformations occurring among children who had left the city. The figures for the two series given in Table II are not corrected for these deficiencies, and may therefore have a slight tendency to understate the true rates. The comparability of the two series does not seem likely to be seriously impaired by these inaccuracies.

Comparison of the two series suggests that the ascertainment of most malformations was at least as complete in the present survey as in the earlier one: defects of the types studied were ascertained in a total of $8 \cdot 3$ per thousand total births in 1950-52 and in $9 \cdot 2$ per thousand in 1957-61, and the rates for most specific malformations were at least as high in $1957-61$ as in 1950-52. The reported incidence of hypospadias in the present series was, however, only half as high as in 1950-52.

The figures for reduction deformities of the limbs require special attention. Anatomically these defects were of many types, and a preliminary examination of our data (Leck and Millar, 1962) suggested that these types might differ from each other epidemiologically: defects of the thumbs and radii were particularly common in 1958, and bilateral defects in 1960-61, but the incidence of other reduction deformities showed little change. For these reasons, we have divided the reduction deformities into several groups which are listed separately in the tables. Details of the individual cases in each group are given in Appendices I and II (for births in 1957-61 and 1950-52 respectively). 
TABLE II

INCIDENCE OF CERTAIN MALFORMATIONS (PER 1,000 TOTAL BIRTHS) IN THE PRESENT SERIES AND IN A STUDY OF BIRTHS IN BIRMINGHAM IN 1950-52

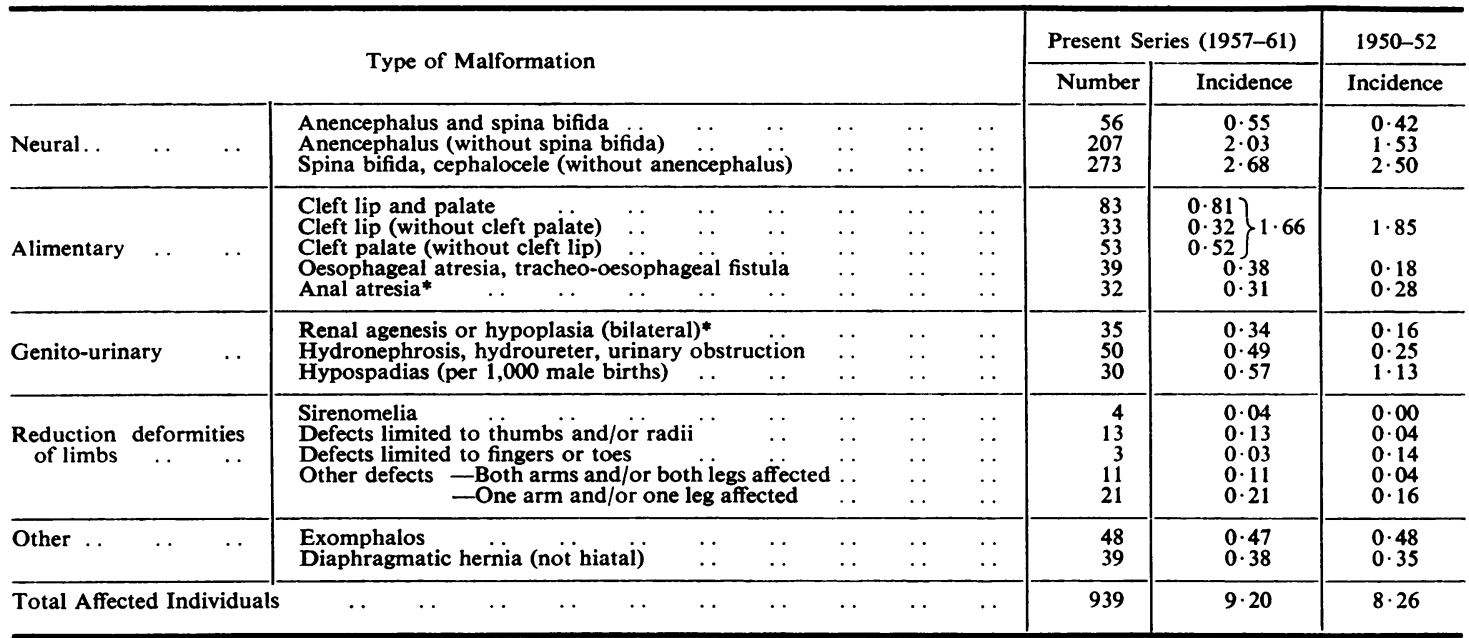

* Excluding cases with sirenomelia.

Reduction deformities limited to fingers and toes were reported only three times in the present series, and those affected were all born in 1961. In 1950-52 such defects were much commoner. As the recording of malformations took place at an earlier age in children born in 1950-52 and 1961 than in those born in 1957-60, it seems likely that finger and toe defects were overlooked except in children who were very young at the time of ascertainment. These defects cause much less disability than the others listed, and are excluded from further consideration.

Bilateral reduction deformities, and defects of the thumbs and radii, were about three times as common in the present series as in the earlier one, but the incidence of unilateral deformities (other than those limited to the digits) showed little change. There were four cases of sirenomelia in 1957-61 and none in 1950-52.

The annual numbers of malformations in the present series are shown in Table III, and the corresponding rates in Table IV (overleaf). As already noted, the figures for all births given in Table I indicate that the children from whom the malformed survivors were drawn were fewer in number than those resident in Birmingham at birth, and the rates given in Table IV are those which would have occurred if the incidence in all survivors had been the same as in those surveyed.

Table IV also contains estimates of the statistical significance of the secular changes in the malformation rates. These estimates were obtained by means

TABLE III

ANNUAL NUMBERS OF MALFORMATIONS

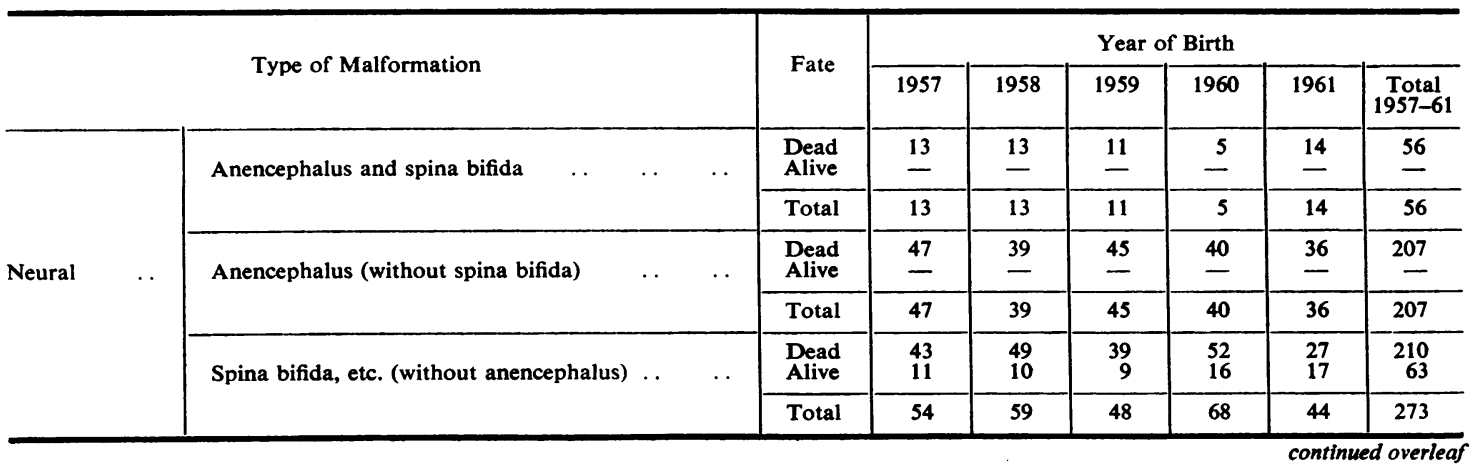


TABLE III-Continued

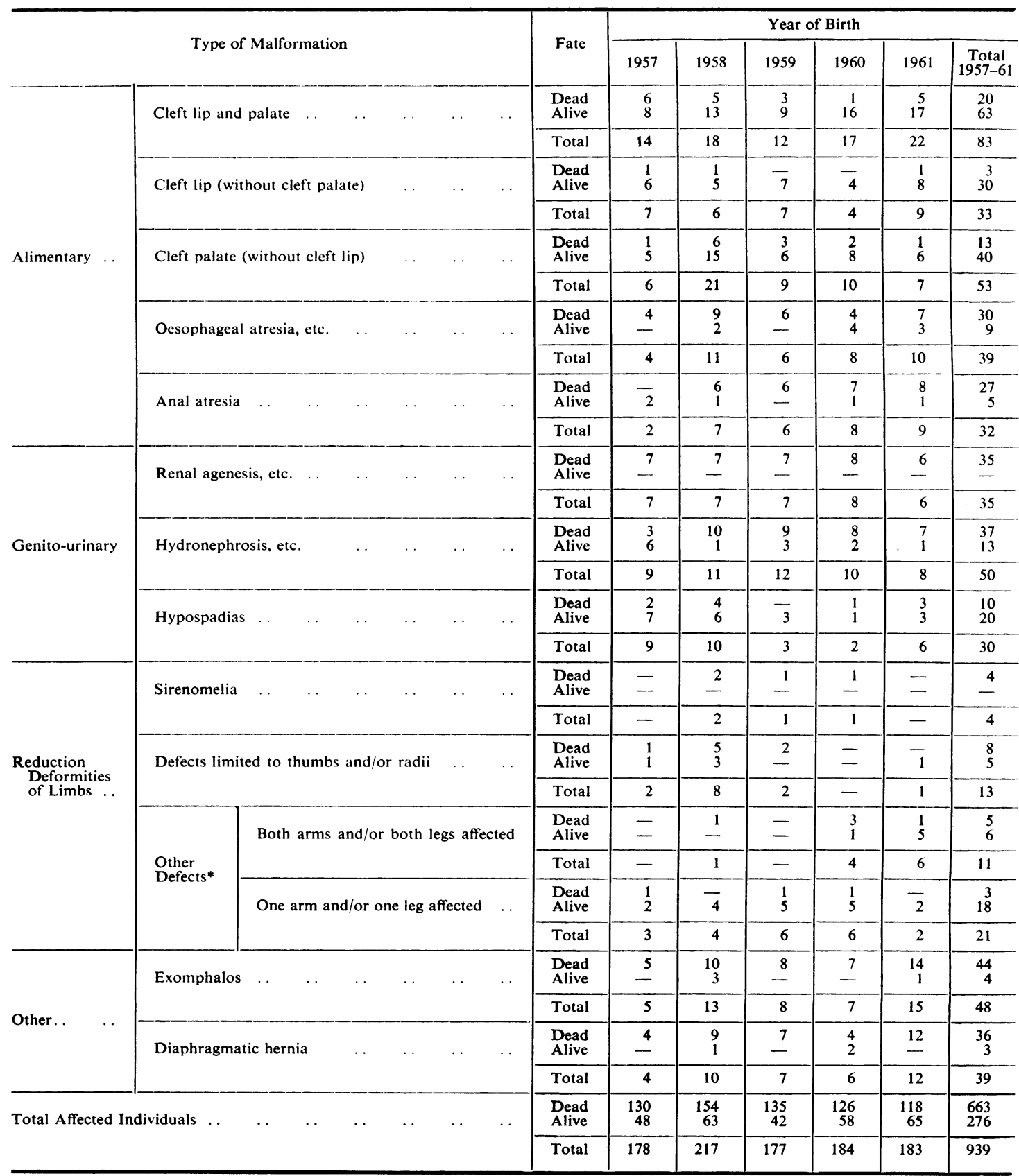

* Excluding defects limited to fingers or toes.

of the $\chi^{2}$ test, ${ }^{*}$ except in the case of the reduction

* The annual numbers of malformations used in the calculation of $\chi^{2}$ were those given in Table III. The numbers in the related populations were estimated from the numbers of malformations in Table III and the corrected rates in Table IV. deformities, which were too infrequent for this test to be accurate. The $P$ value given for each reduction deformity indicates the significance of the difference between the highest and mean numbers affected 
TABLE IV

ANNUAL INCIDENCE OF MALFORMATIONS (PER 1,000 TOTAL BIRTHS)

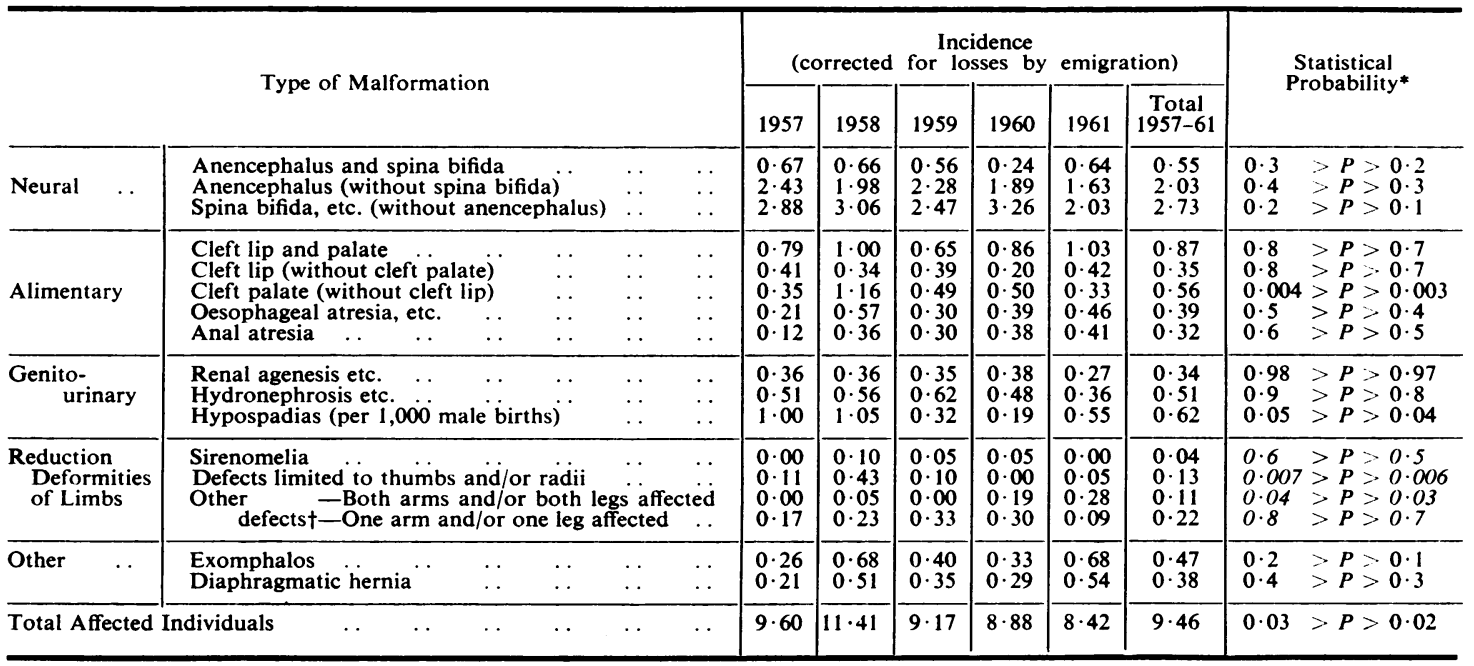

* Probability values were estimated by the $\chi^{2}$ test, except for those shown in italic type. These, which relate to the less common malformations (those of which the expected annual numbers were not all greater than five), were estimated by the test for epidemic disturbances described by Edwards (1958).

† Excluding defects limited to fingers or toes.

annually. The method used is described by Edwards (1958) in his discussion of short-term trends.

Malformations of the types studied occurred in a substantially higher proportion of all births in 1958 (11.4 per thousand) than in 1957 and 1959-61 (8.4-9.6 per thousand). As the National Perinatal Mortality Survey took place in 1958, it was at first thought that the high incidence in this year might indicate that this Survey had improved the ascertainment of malformations in stillbirths and neonatal deaths. A more detailed analysis of the data did not support this suggestion. In the Mortality Survey, clinical data on stillbirths and neonatal deaths were collected in March-May, 1958, and necropsy data in March only (Butler, 1961). The incidence of malformed stillbirths and neonatal deaths in Birmingham was lower at this time than in the rest of 1958 (Table V), and therefore the increase in the malformation rate in 1958 cannot be ascribed to the Mortality Survey.

Five specific malformations occurred more often in 1958 than in any other year. These were cleft palate without cleft lip, oesophageal atresia and tracheo-oesophageal fistula, hypospadias, sirenomelia, and reduction deformities of the thumbs and radii. The secular changes shown by three of these malformations were formally significant-at the 5 per cent. level for hypospadias, and at the 1 per cent. level for radial and thumb defects and cleft palate. The only other statistically significant
TABLE V

MALFORMATIONS ASCERTAINED IN STILLBIRTHS AND NEONATAL DEATHS IN BIRMINGHAM DURING THE NATIONAL PERINATAL MORTALITY SURVEY AND THE REMAINDER OF 1958

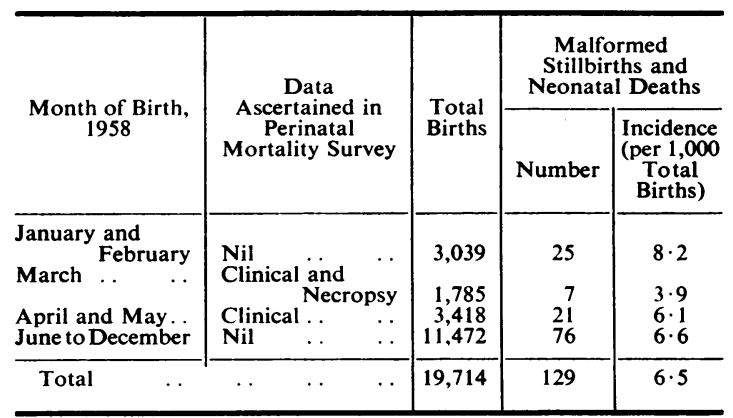

secular variation observed was in respect of miscellaneous reduction deformities affecting both arms or both legs, which increased in incidence in 1960-61; this increase is examined elsewhere (Leck and Millar, 1962).

The secular distribution of the malformations that were commoner in 1958 than in other years is shown in more detail in the Figure (overleaf). This indicates that hypospadias was particularly common in the second half of 1957 and the first half of 1958; the incidence of cleft palate was high from late 1957 to early 1959; and twelve of the thirteen cases of radial and thumb defects occurred between the middle of 1957 
CLEFT PALATE

[ WITHOUT CLEFT LIP]
oEsophageal atresia, TRACHEO-OESOPHAGEAL FISTULA

HYPOSPADIAS

SIRENOMELIA

REDUCTION DEFORMITIES LIMITED TO THUMBS AND RADII

ALL INDIVIDUALS WITH THE abOVE maLformations
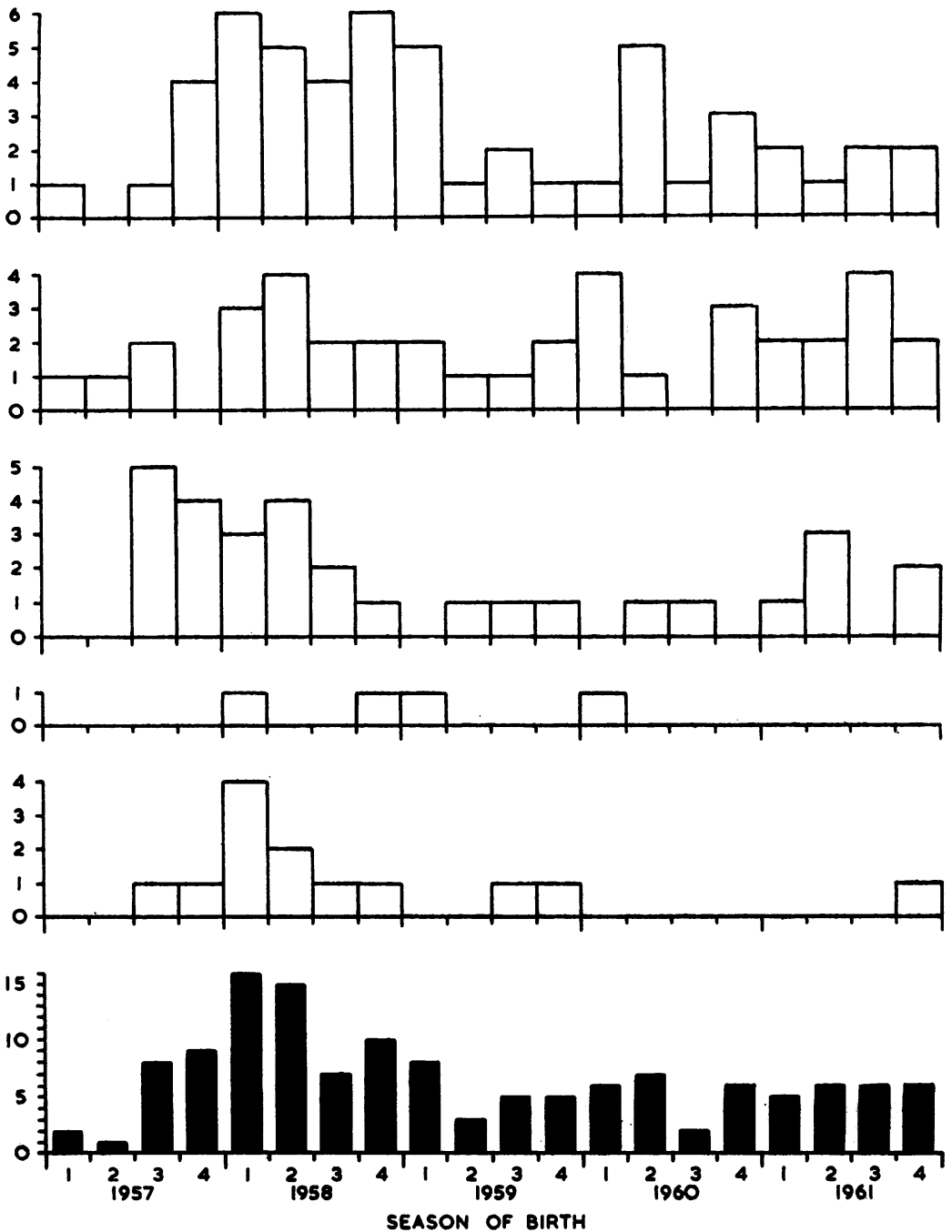

SEASON OF BIRTH

FIGURE.-Number of individuals affected by malformations which were more common in 1958 than in any other year.

and the end of 1959, seven of them in the first half of 1958. There were no clearly defined clusters of births with oesophageal atresia or sirenomelia. The frequency of all births affected by one or more of the five defects was high throughout the period July, 1957 to March, 1959.

In spite of the differences between the distributions for specific malformations illustrated in the Figure, it is conceivable that several or all of the increases in incidence shown by the five defects within the period July, 1957 to March, 1959, were due to a single cause. If an influence capable of causing several of these malformations had been especially prevalent at that time, it would probably have produced a cluster of births with more than one of the defects. The frequency of births of this kind is examined in Table VI (opposite). Combinations of the five defects occurred in four births (116 per million) in July, 1957 to March, 1959, and in one (15 per million) in the rest of 1957-61. The rates to be expected if all combinations were fortuitous are only 1.45 and 0.25 per million respectively. ${ }^{*}$ The ratio of the observed to the expected rate, which is a

* The expected rates are those that would occur if the incidence of every combination of malformations was equal to the product of the rates at which these malformations occurred separately. 
TABLE VI

FREQUENCY OF ASSOCIATION BETWEEN MALFORMATIONS LISTED IN THE FIGURE

\begin{tabular}{l|c|c}
\hline $\begin{array}{c}\text { Individuals with More than } \\
\text { One of the Listed } \\
\text { Malformations }\end{array}$ & $\begin{array}{c}\text { July, 1957, to } \\
\text { March, 1959 } \\
\text { (34,395 Births) }\end{array}$ & $\begin{array}{c}\text { Jan. to June, 1957 } \\
\text { Apr., 1959 to } \\
\text { Dec., 1961 } \\
\text { (67,647 Births) }\end{array}$ \\
\hline $\begin{array}{c}\text { Number Observed \% } \\
\text { Incidence Observed (per mil- } \\
\text { lion births) }\end{array}$ & $4^{*}$ & $1 \dagger$ \\
$\begin{array}{c}\text { Incidence Expected (per mil- } \\
\text { lion births) } \\
\text { Ratio (Observed : Expected) }\end{array}$ & 116 & 15 \\
\hline
\end{tabular}

* Tracheo-oesophageal fistula and absence of thumbs; tracheooesophageal fistula and absence of left thumb; cleft palate, hypospadias and absence of first metacarpal; cleft palate and hypospadias.

$\dagger$ Cleft palate and hypospadias.

measure of the strength of the association between the five malformations, was only slightly higher in July, 1957, to March, 1959 (80) than in the rest of the 1957-61 period (60). In view of this equivocal result, and the fact that the periods of highest incidence for the different malformations did not coincide exactly, it would be unwise to postulate a common cause for all these increases. There may however be a relationship between the high rates for 1958 shown by reduction deformities of the thumbs and radii and by some other malformations, since radial and thumb deformities generally occur in association with other defects (Birch-Jensen, 1949) and this association may indicate a common aetiology. In the present series eleven of the thirteen cases of radial and thumb defects had additional malformations (Appendix I).

Unfortunately, we are not in a position to confirm from other sources the high malformation rates reported here for 1958 , or to determine whether they occurred elsewhere. The figures for causes of stillbirths and infant deaths published by Registrars General are unhelpful because the malformations which showed significant increases-cleft palate, hypospadias, and radial and thumb defects-are all non-lethal. But although they cannot be verified from other data, the findings for cleft palate and radial and thumb defects are very unlikely to be due to random variations or biassed ascertainment: both in survivors and in dead children these malformations were substantially commoner in 1958 than in any other year (Table III), and as different methods of ascertainment were used in these two groups of children there is no source of bias which could affect both. The evidence for non-random changes in the incidence of hypospadias is less convincing: the variation reported was only just significant at the 5 per cent. level, and as the rate for the whole period was only half as high as in 1950-52 (Table II) it seems likely that ascertainment was incomplete.
Three kinds of influences-ionizing radiations, infections, and drugs-are at present known to be capable of producing short-term variations in the incidence of human malformations (Warkany and Kalter, 1961). The radiocative fall-out rate was highest in 1959 (Pierson, Crooks, and Fisher, 1960) and cannot therefore be related to the high incidence of cleft palate, hypospadias, and radial and thumb defects in and around 1958. As the increases in incidence lasted for a year or more, they are unlikely to have been due to an epidemic of infectious disease. The possibility that they were caused by a drug or drugs should be taken rather more seriously, since drugs frequently fall into disuse a year or two after their introduction. Also, all three malformations have been reported in association with specific drugs under circumstances which suggest causality. Cleft palate is often found in the offspring of mice and rabbits who have received cortisone during pregnancy (Fraser and Fainstat, 1951; Fainstat, 1954) and four cases have been described among children whose mothers took the drug while they were pregnant (Bongiovanni and McPadden, 1960). After the administration of large doses of oestrogen in pregnancy, hypospadias occurs regularly in rats (Greene, Burrill, and Ivy, 1940) and has been reported once in man (Kaplan, 1959). Radial and thumb defects, and most of the malformations that were associated with them in the present series (e.g. unilateral renal agenesis, hydroureter, oesophageal atresia), have been observed in association with the taking of thalidomide (Lenz and Knapp, 1962). However, thalidomide had not been introduced when the children born in 1958 passed through the early stages of intra-uterine life, and we have no evidence that any other drug with teratogenic effects was especially popular at that time.

\section{Malformations Which may be Related to THALIDOMIDE}

In recent years large increases in the incidence of microtia and ectromelia have occurred in many countries, and it is generally agreed that these increases are due at least in part to the taking of the sedative thalidomide in early pregnancy (Leck and Millar, 1962; Lenz and Knapp, 1962; Saller and Unglaub, 1962; Smithells, 1962; Taussig, 1962; Weicker and Hungerland, 1962). In the present series there were three children with absence of the auricle or external auditory meatus, and ten with bilateral reduction deformities of the limbs of the type previously described in association with thalidomide. All were born in 1960-61. They are discussed in our earlier report. 
Many children with ectromelia or microtia due to thalidomide also have other malformations, and Table VII gives a list of those reported more than once in the combined series of McBride (1961), Wiedemann (1961), Kenny (1962), Leck and Millar (1962), Lenz and Knapp (1962), Morgan (1962), Pfeiffer and Kosenow (1962a,b), Pliess (1962), Schönenberg (1962), Smithells (1962), and Speirs (1962). The results of the present survey appear to be the only data so far available on the total incidence of the defects listed in Table VII before and after the introduction of thalidomide. We have therefore examined the data to determine whether these defects have become more common in children showing no other evidence of injury by thalidomide. The thirteen children born in 1960-61 with microtia or bilateral ectromelia were excluded.

Figures for some of the defects listed in Table VII (cleft palate, bilateral renal agenesis and hypoplasia, and oesophageal and anal atresia) were given above. we had no cases) are shown in Table VIII (external malformations) and Table IX (internal malformations). The annual figures given for external malformations include cases in both living and dead propositi, but those for internal malformations relate only to cases in which stillbirth or neonatal death occurred. The annual figures for internal malformations in survivors are omitted because they are not comparable: the ascertainment of many malformations increases Data for the remainder (apart from those of which

TABLE VII

OTHER MALFORMATIONS REPORTED IN ASSOCIATION WITH REDUCTION DEFORMITIES OF LIMBS AND EARS DURING THE RECENT EPIDEMIC

\begin{tabular}{|c|c|c|c|}
\hline \multicolumn{3}{|c|}{ Malformation } & \multirow{2}{*}{$\begin{array}{c}\begin{array}{c}\text { Number } \\
\text { Reported }\end{array} \\
6 \\
4 \\
3 \\
5\end{array}$} \\
\hline \multirow{2}{*}{ External } & $\begin{array}{l}\text { Musculo- } \\
\text { skeletal }\end{array}$ & $\begin{array}{l}\text { Polydactyly } \ldots \\
\text { Syndactyly } \ldots \\
\text { Thumb of three phalanges. } \\
\text { Talipes }\end{array}$ & \\
\hline & $\begin{array}{l}\text { Special } \\
\text { sensory }\end{array}$ & \begin{tabular}{lcc}
\multicolumn{4}{l}{$\begin{array}{l}\text { Anophthalmos, microphthal- } \\
\text { mos }\end{array}$} & $\ldots$ & $\ldots$ & $\ldots$ \\
Coloboma & $\ldots$ & $\ldots$ \\
Accessory auricles & $\ldots$ & $\ldots$
\end{tabular} & $\begin{array}{r}17 \\
3 \\
2\end{array}$ \\
\hline \multirow{6}{*}{ Internal } & Alimentary & $\begin{array}{l}\text { Cleft palate (without cleft lip) } \\
\text { Oesophageal atresia } \\
\text { Duodenal atresia } \\
\text { Duodenal stenosis } \\
\text { Absence of appendix } \\
\text { Intestinal malrotation } \\
\text { Abnormally lax mesentery. } \\
\text { Dystonia of large intestine. } \\
\text { Anal atresia. } \\
\text { Absence of gall bladder } \\
\text { Atresia of common bile duct } \\
\text { Abnormal lobulation of liver }\end{array}$ & $\begin{array}{r}2 \\
2 \\
16 \\
17 \\
9 \\
10 \\
2 \\
3 \\
17 \\
10 \\
3 \\
5\end{array}$ \\
\hline & Cardiac .. & $\begin{array}{l}\text { Ventricular septal defect, } \\
\text { Fallôt's tetralogy }\end{array}$ & 14 \\
\hline & $\begin{array}{l}\text { Genito- } \\
\text { urinary }\end{array}$ & $\begin{array}{l}\text { Renal agenesis or hypoplasia } \\
\text { Horseshoe kidney } \\
\text { Hydronephrosis, hydroureter } \\
\text { Bicornuate or double uterus } \\
\text { Vaginal atresia }\end{array}$ & $\begin{array}{l}8 \\
2 \\
5 \\
8 \\
5\end{array}$ \\
\hline & Neural $\ldots$ & Hydrocephalus & 4 \\
\hline & Respiratory & $\begin{array}{l}\text { Choanal atresia . . . } \\
\text { Abnormal lobulation of lungs }\end{array}$ & $\begin{array}{l}4 \\
7\end{array}$ \\
\hline & Skeletal & Dislocation of hips . . & 7 \\
\hline
\end{tabular}

TABLE VIII

FREQUENCY OF EXTERNAL MALFORMATIONS LISTED IN TABLE VII (INDIVIDUALS WHOSE LIMBS OR EARS EXHIBITED REDUCTION DEFORMITIES SUGGESTIVE OF THALIDOMIDE ADMINISTRATION ARE EXCLUDED)

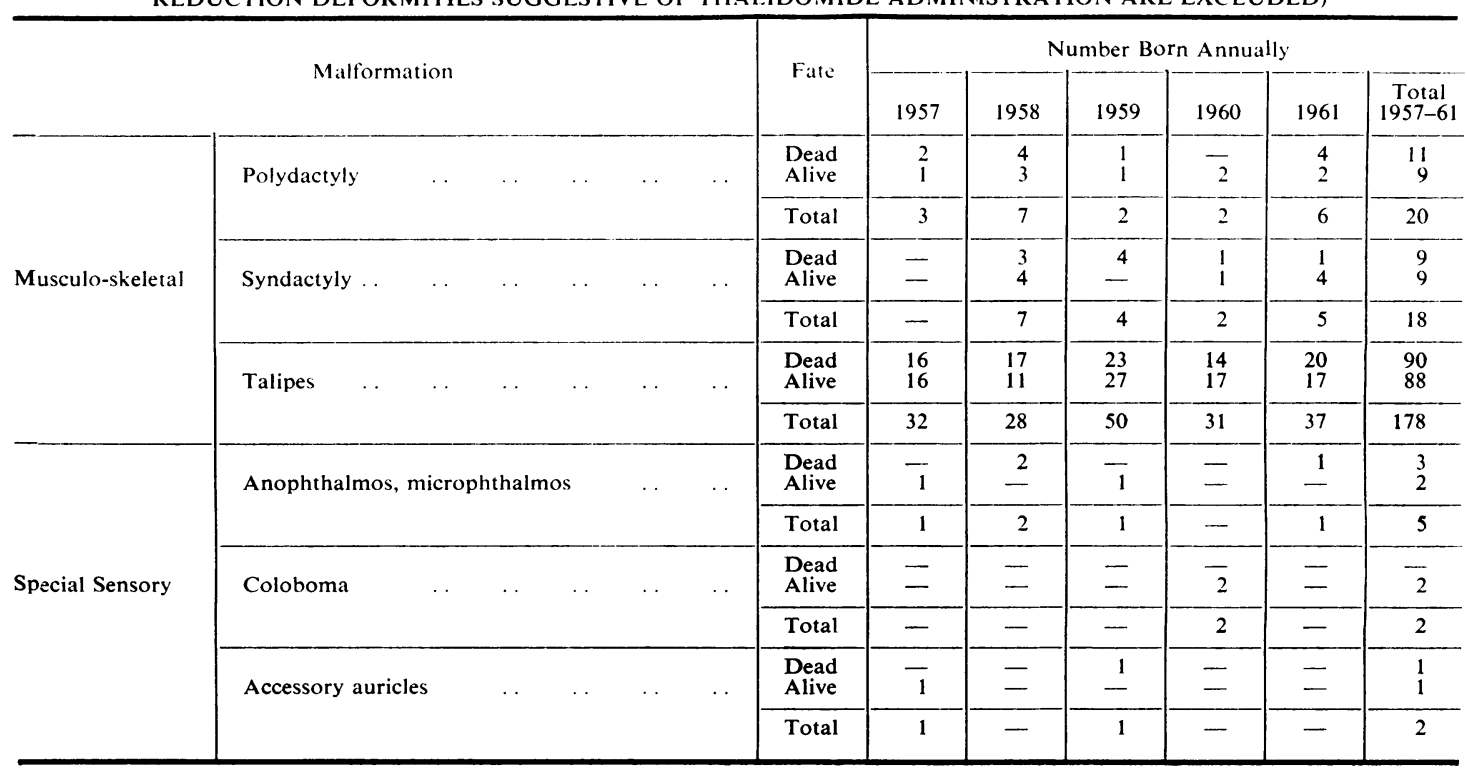

응 


\section{TABLE IX}

STILLBIRTHS AND NEONATAL DEATHS ASSOCIATED WITH CERTAIN INTERNAL MALFORMATIONS LISTED IN TABLE VII. (INDIVIDUALS WHOSE LIMBS OR EARS EXHIBITED REDUCTION DEFORMITIES SUGGESTIVE OF THALIDOMIDE ADMINISTRATION ARE EXCLUDED)

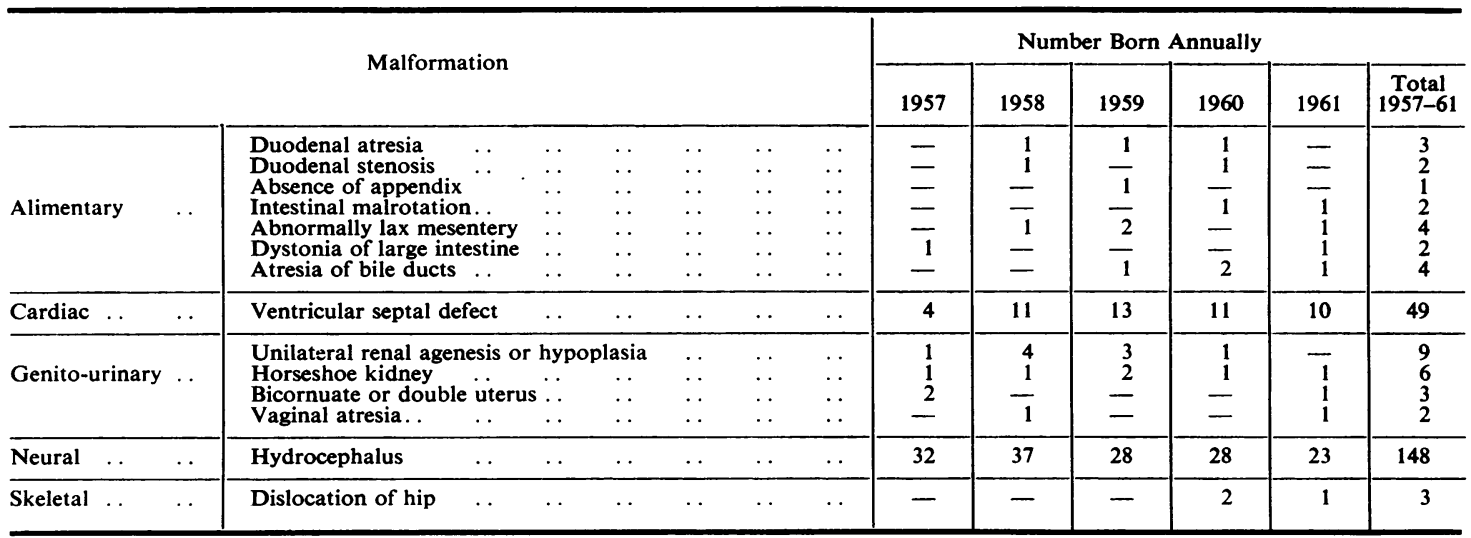

with age, and survivors born in different years were not of the same age at the time of the survey.

The incidence of all the types of malformations mentioned in Table VII (including those not listed in Tables VIII and IX) is examined in Table X. The commonest defects-hydrocephalus and talipesare considered separately, and the remainder are grouped.

The rates for talipes and for individuals with other external malformations were no higher in 1960-61 than in 1957-58. Ascertainment was probably at least as good among births at the end of the 5-year period as at the beginning, since external defects are generally noticed at birth but often require no treatment after the neonatal period and may then be forgotten.

The rates for hydrocephalus and for individuals with other internal malformations were highest in 1958 and declined in each subsequent year. Although these rates relate only to instances in which stillbirth or neonatal death occurred, their decline seems too great to be ascribed wholely to improvements in survival. More probably total incidence has also declined.

TABLE $\mathbf{X}$

INCIDENCE (PER 1,000 TOTAL BIRTHS) OF INDIVIDUALS WITH MALFORMATIONS LISTED IN TABLE VII. (INDIVIDUALS WHOSE LIMBS OR EARS EXHIBITED REDUCTION DEFORMITIES SUGGESTIVE OF THALIDOMIDE ADMINISTRATION ARE EXCLUDED)

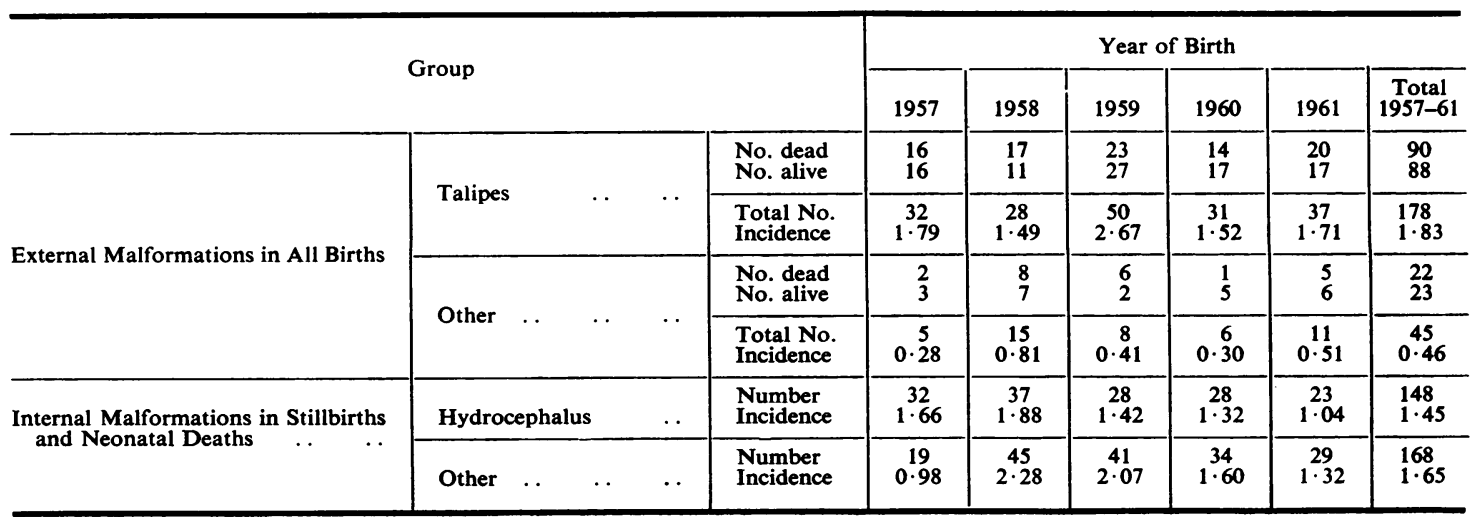


TABLE XI

STILLBIRTHS AND NEONATAL DEATHS ASSOCIATED WITH TWO OR MORE MALFORMATIONS OF TYPES LISTED IN TABLE VII. (INDIVIDUALS WHOSE LIMBS OR EARS EXHIBITED REDUCTION DEFORMITIES SUGGESTIVE OF THALIDOMIDE ADMINISTRATION HAVE BEEN EXCLUDED)

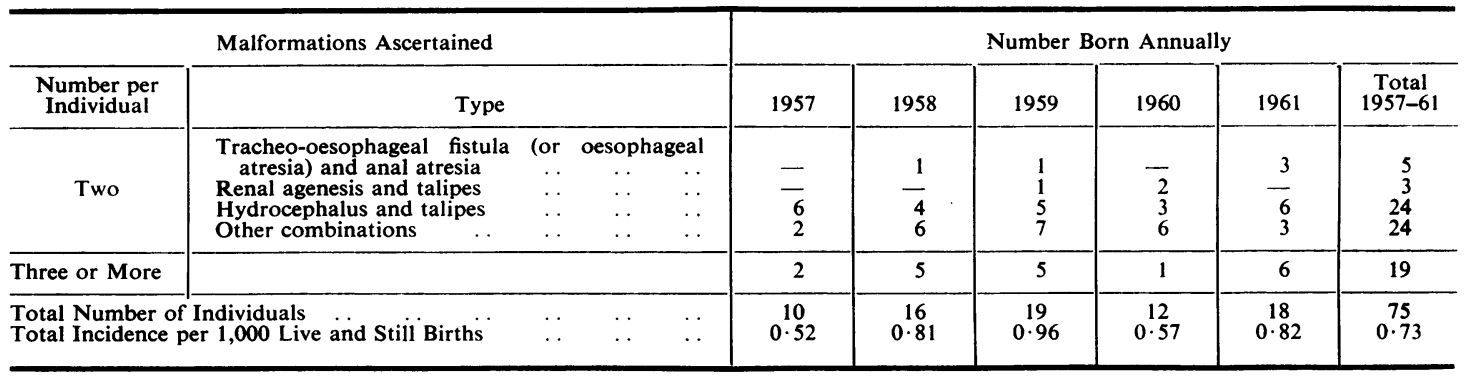

Children with limb and ear defects due to thalidomide frequently have more than one of the malformations listed in Table VII. The frequency of combinations of these malformations in other children (excluding those who survived more than one month) is shown in Table XI. The three commonest combinations-tracheo-oesophageal fistula and anal atresia, renal agenesis and talipes, and hydrocephalus and talipes-are listed separately. All three have often been observed before (e.g. McKeown and Record, 1960; Potter, 1961; Hays, 1962). The incidence of all combinations was as low in 1960-61 (when the risks of exposure to thalidomide were highest) as in the other years.

Evidence from Germany, where thalidomide was more widely used than elsewhere, indicates that a few children with malformations listed in Table VII but with normal limbs and ears have been born after the administration of the drug. Lenz and Knapp (1962) mentioned a mother who took the drug in pregnancy and had twins, one with phocomelia and the other with duodenal and anal atresia and normal limbs. However, the limbs and ears were normal in only 2 to 4 per cent. of these authors' series of malformed children born after the administration of thalidomide, and limb and ear defects appear to have been the only malformations of which the incidence increased regularly during the period 1959-61 in Bavaria (Saller and Unglaub, 1962). These findings, and our own evidence that the malformations listed in Table VII have not become more common, suggest that thalidomide does not usually cause these defects without also stunting the limbs or ears.

\section{SUMMARY}

Data obtained from Local Authority records, hospital and necropsy reports, and Health Visitors' returns were used to estimate the annual incidence of various malformations among Birmingham children born in 1957-61.

Formally significant variations in incidence, with maxima in 1958 , were shown by the figures for all individuals with fully ascertainable malformations and for three specific defects-cleft palate, hypospadias, and reduction deformities of the thumbs and radii. A more detailed analysis showed that the incidence of each of these three defects had remained high for a year or more between July, 1957, and March, 1959. Possible reasons for the increase are discussed.

Microtia and bilateral ectromelia were commonest in 1960-61. The incidence of the other defects which thalidomide may cause showed no increase in children whose limbs and ears were of normal size.

Most of the data used in this inquiry were either collected or abstracted from existing records by Mrs. Eileen Armstrong, Miss Ann Cooper, Miss Ida Giles, Mrs. Betty Mann, and the Health Visitors of the City of Birmingham, with the help of Miss Milner, Miss Greening, and Miss Cook. Hospital and necropsy records were made available to us by Mr. O. T. Mansfield, F.R.C.S., Dr. K. W. Cross, the pathologists and records officers of local hospitals, and the City of Birmingham Coroner. We are grateful to all these people for their ready cooperation.

\section{REFERENCES}

Birch-Jensen, A. (1949). "Congenital Deformities of the Upper Extremities”, trans. E. Aagesen, p. 88. Andelsbogtrykkeriet i Odense.

Bongiovanni, A. M., and McPadden, A. J. (1960). Fertil. and Steril., 11, 181.

Butler, N. (1961). Proc. roy. Soc. Med., 54, 1089.

Edwards, J. H. (1958). Brit. J. prev. soc. Med., 12, 115.

Fainstat, T. (1954). Endocrinology, 55, 502.

Fraser, F. C., and Fainstat, T. D. (1951). Pediatrics, 8, 527. 
Greene, R. R., Burrill, M. W., and Ivy, A. C. (1940). Amer. J. Anat., 67, 305.

Gregg, N. M. (1941). Trans. ophthal. Soc. Aust., 3, 35.

Hays, D. M. (1962). Amer. J. Dis. Child., 103, 765.

Kaplan, N. M. (1959). New Engl. J. Med., 261, 641.

Kenny, S. (1962). Brit. J. Radiol., 35, 462.

Leck, I. M. (1961). "Malformations in a Population observed for Five Years after Birth." Ph.D. Thesis, University of Birmingham.

- and Millar, E. L. M. (1962). Brit. med. J., 2, 16.

Lenz, W. (1961). Dtsch. med. Wschr., 86, 2555.

- and Knapp, K. (1962). Ibid., 87, 1232.

McBride, W. G. (1961). Lancet, 2, 1358.

McKeown, T., and Record, R. G. (1960). In "Ciba Foundation Symposium on Congenital Malformations," ed. G. E. W. Wolstenholme and C. M. O'Connor, p. 2. Churchill, London.

Morgan, B. C. (1962). Brit. med. J., 1, 792.

Pierson, D. H., Crooks, R. N., and Fisher, E. M. R. (1960). "Radioactive Fall-out in Air and Rain."
Atomic Energy Research Establishment, Harwell. (Her Majesty's Stationery Office, London).

Pfeiffer, R. A., and Kosenow, W. (1962a). Lancet, 1, 45. - (1962b). Münch. med. Wschr., 104, 68.

Pliess, G. (1962). Lancet, 1, 1128.

Potter, E. L. (1961). "Pathology of the Fetus and Infant", 2nd ed., p. 594. Year Book Medical Publishers, Chicago.

Saller, K., and Unglaub, I. (1962). Münch. med. Wschr., $104,1219$.

Schönenberg, H. (1962). Bibl. paediat. (Basel), (suppl. to Ann. Paediat.), 80.

Smithells, R. W. (1962). Lancet, 1, 1270.

Speirs, A. L. (1962). Ibid., 1, 303.

Taussig, H. B. (1962). J. Amer. med. Ass., 180, 1106.

Warkany, J., and Kalter, H. (1961). New Engl. J. Med., 265, 993 and 1046.

Weicker, H., and Hungerland, H. (1962). Dtsch. med. Wschr., 87, 992.

Wiedemann, H.-R. (1961). Med. Welt, No. 37, p. 1863.

\section{APPENDIX I}

\section{REDUCTION DEFORMITIES OF THE LIMBS IN CHILDREN BORN IN 1957-61}

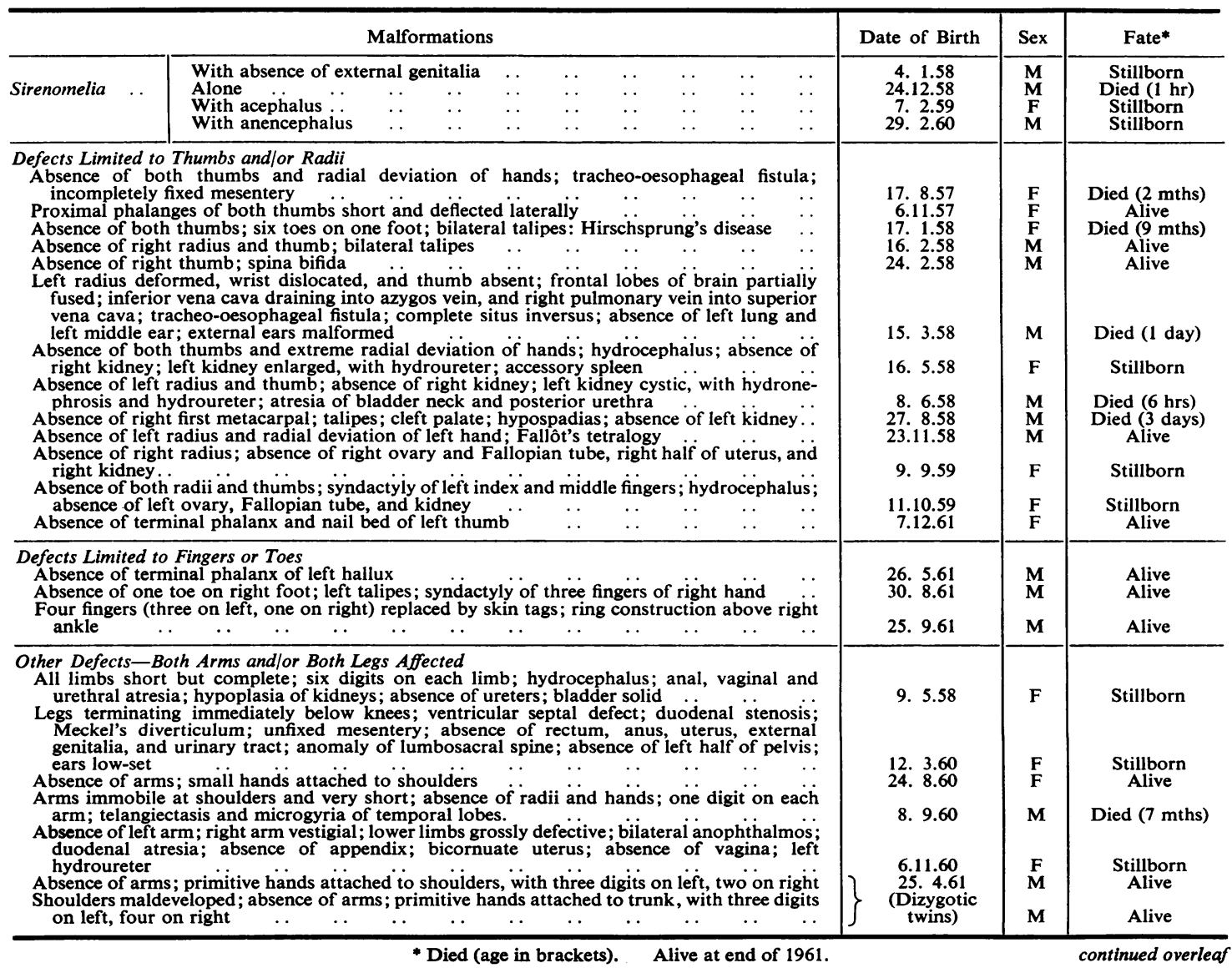


APPENDIX I. REDUCTION DEFORMITIES OF THE LIMBS IN CHILDREN BORN IN 1957-61 (continued).

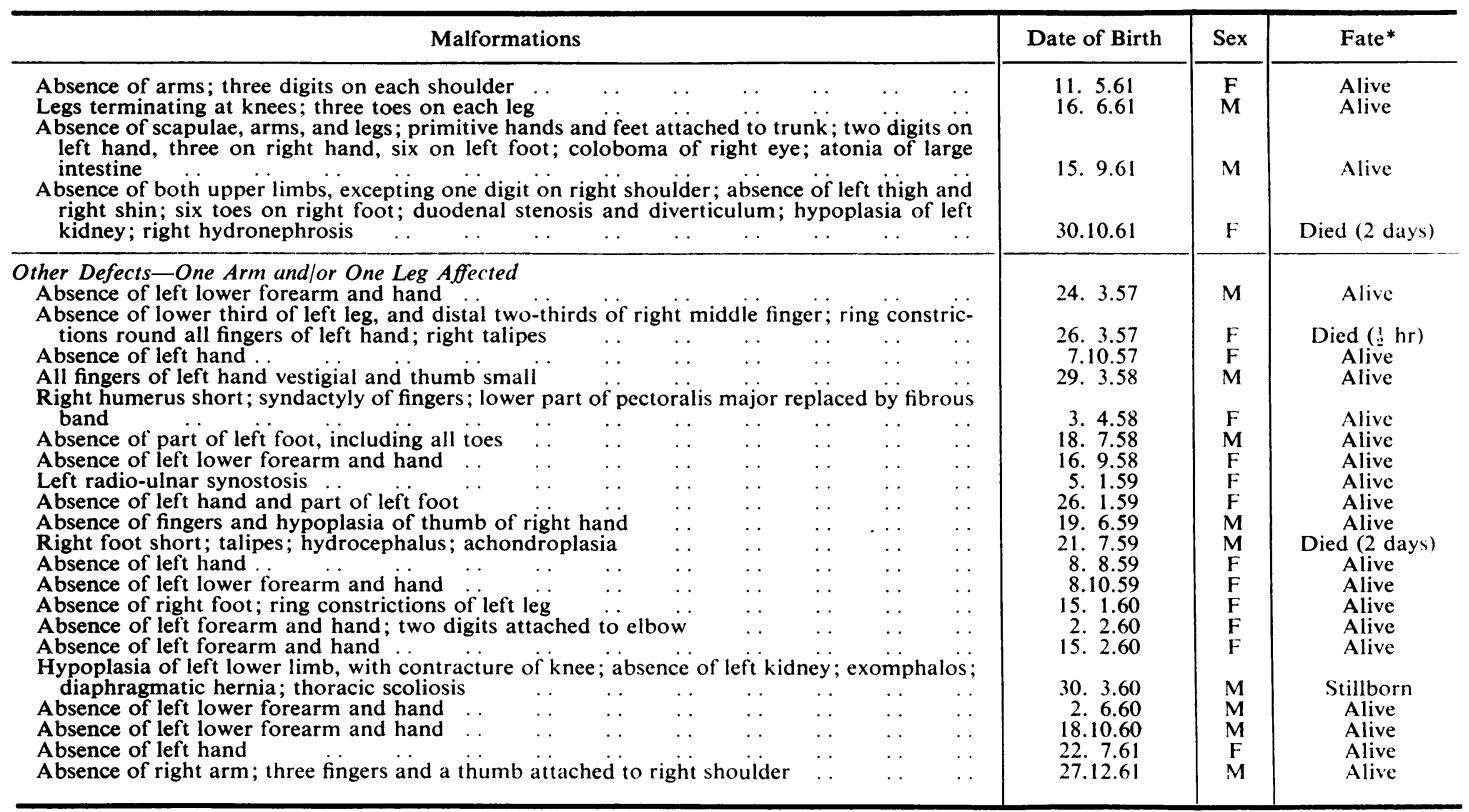

* Follow-up to the end of 1961 . Age at death in brackets where applicable.

APPENDIX II

REDUCTION DEFORMITIES OF THE LIMBS IN CHILDREN BORN IN 1950-52

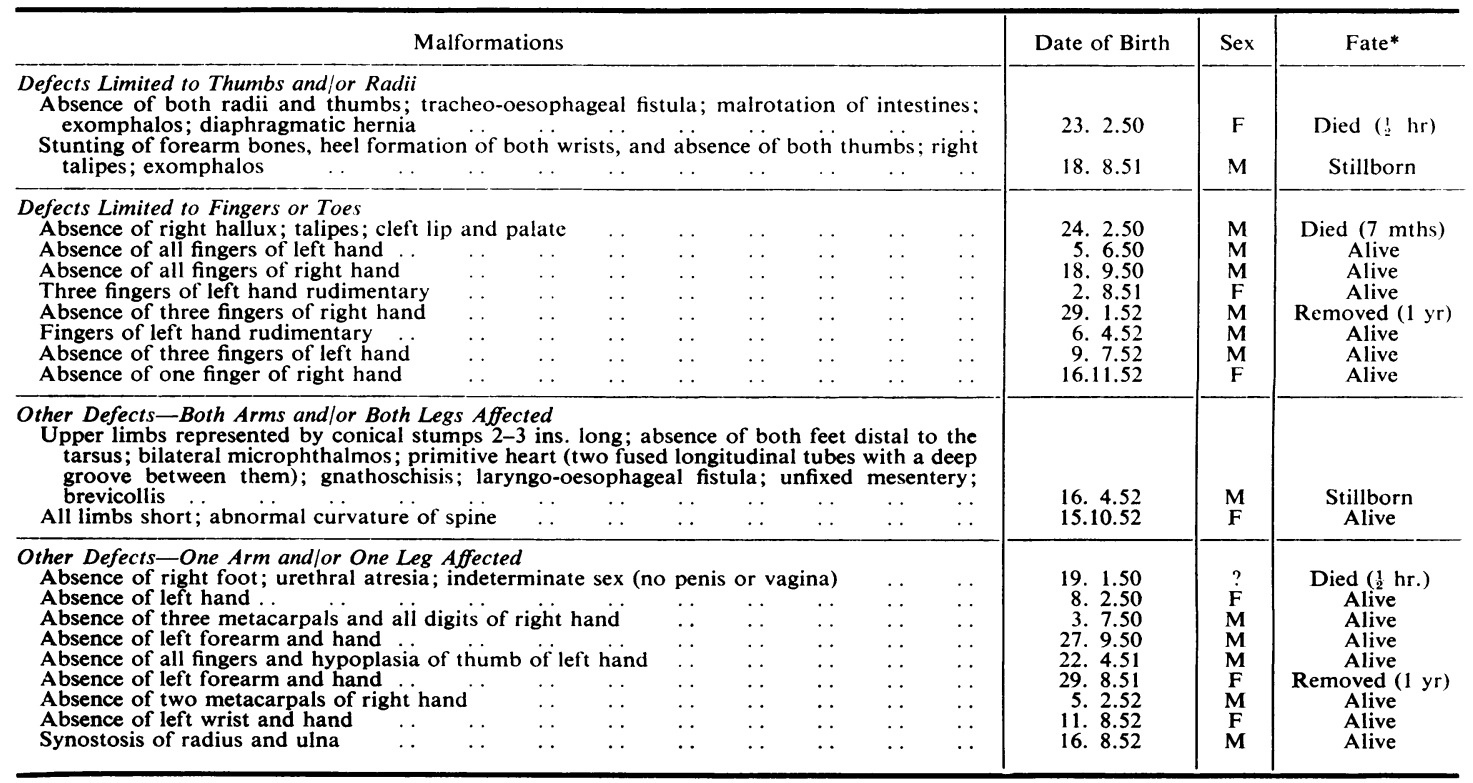

* 5-year follow-up.

Age at death or removal from city in brackets where applicable. 